\title{
Fabrication of In-Situ Intermetallic Compound Dispersed Aluminum Matrix Composites by Addition of Metal Powders*
}

\author{
Mitsuaki Matsumuro and Tadashi Kitsudo \\ Technology Research Institute of Osaka Prefecture
}

A new process was proposed to fabricate intermetallic compound reinforced Al matrix composites by the reaction between metal powders and molten $\mathrm{Al}$. The Ni powders were added gradually onto the surface of the molten pure $\mathrm{Al}$ by stirring. The $\mathrm{Al}_{3} \mathrm{Ni}$ particles, which are smaller than the added Ni powder, were in situ formed and homogeneously dispersed in the Al. The processing temperature was lower and the stirring time was shorter than those of the conventional vortex method for fabricating non-metal $\left(\mathrm{Al}_{2} \mathrm{O}_{3}, \mathrm{SiC}\right.$ etc) reinforced $\mathrm{Al}$ matrix composites. The effects of the processing variables, such as processing temperature, size of the Ni powder, and stirring time, on the formation and dispersion behavior of $\mathrm{Al}_{3} \mathrm{Ni}$ were investigated. It was found that the size of the $\mathrm{Al}_{3} \mathrm{Ni}$ decreased with the decreasing processing temperature and stirring time. The process was also applied to $\mathrm{Ti}, \mathrm{Zr}, \mathrm{Cr}, \mathrm{Mo}, \mathrm{W}$ and $\mathrm{Fe}$ powders. $\mathrm{Al}_{3} \mathrm{Ti}, \mathrm{Al}_{3} \mathrm{Zr}, \mathrm{Al}_{7} \mathrm{Cr}$ and $\mathrm{Al}_{12} \mathrm{Mo}$ were formed and homogeneously dispersed, but the others failed. The size of the intermetallic compounds significantly depended on the specific elemental metal powder. The dispersion of the intermetallic compounds was affected by the oxidation of the metal powders. This process was applicable to the JIS AC8A alloy for forming the $\mathrm{AC} 8 \mathrm{~A}-\mathrm{Al}_{3} \mathrm{Ni}$ composite. [doi:10.2320/matertrans.47.2972]

(Received March 17, 2006; Accepted October 5, 2006; Published December 15, 2006)

Keywords: metal matrix composite, aluminum, nickel, powder, $\mathrm{Al}_{3} \mathrm{Ni}$, intermetallic compounds, solidification, microstructure

\section{Introduction}

The requirement for lighter-weight materials in recent years has led to the adoption of aluminum as a substitute for steel or cast iron in material processing. To facilitate these efforts, material designers need to create Al alloys with advanced functions. A method to accomplish this is to apply ceramic-particulate-reinforced Al matrix composites. Composites of this type have been used in materials for disk break rotors now in practical use. ${ }^{1,2)}$

Ceramic-particulate-reinforced Al matrix composites are generally produced by powder metallurgy or casting. Both methods have drawbacks. Powder metallurgy is costly. Casting is a good deal simpler than powder metallurgy, but the poor wettability of ceramics by molten $\mathrm{Al}$ makes it difficult to incorporate ceramics into molten $\mathrm{Al}$ and then homogeneously disperse them. The best ways to overcome these difficulties are to use metal-coated ceramics, ${ }^{3)}$ to add surface-active elements to the $\mathrm{Al}$ matrix, ${ }^{4,5)}$ and to apply the method known as compocasting. ${ }^{6)}$ In these processes, however, brittle reaction products tend to be generated at the reinforcement-matrix interface, ${ }^{7)}$ and it is difficult to incorporate fine particles into molten $\mathrm{Al}^{8}{ }^{8}$

Another approach is to apply in-situ processes for the synthesis of the reinforcements. For example, TiC can be dispersed by adding $\mathrm{SiC}$ or $\mathrm{Al}_{4} \mathrm{C}_{3}$ to the molten $\mathrm{Al}-\mathrm{Ti}$ alloy, ${ }^{9,10)}$ and $\mathrm{Al}_{2} \mathrm{O}_{3}$ can be dispersed by adding oxides to a molten $\mathrm{Al}$ alloy. ${ }^{11,12)}$ In both processes, the reinforcements formed in situ are thermodynamically stable and can be homogeneously dispersed. Better still, the underlying mechanism in these processes, particle formation, is expected to assure a clean reinforcement-matrix interface entirely free from inclusions (e.g., oxides). Yet both processes also have drawbacks; they can only succeed when high temperatures are maintained, and the reaction by-products remain in the $\mathrm{Al}$

*This Paper was Originally Published in Japanese in J. JFS 77 (2005) 731737. matrix as impurities.

In this study we sought to fabricate Al matrix composites in situ by adding particles in a vortex process. Specifically, we used transition metal powders with a relatively high wettability by molten Al. By adding these metal powders to the molten $\mathrm{Al}$, we induced a reaction to form intermetallic compounds via the vortex process. Our intention was to synthesize intermetallic compounds in the molten $\mathrm{Al}$ and homogeneously disperse them.

Many investigations have focused on the synthesis of composites through the reaction between a metal powder and Al. Those includes the reactive infiltration process, ${ }^{13)}$ a method involving the combustion synthesis of $\mathrm{TiC}$ and spontaneous infiltration, and the methods in which $\mathrm{Al}_{3} \mathrm{Ti}$ can be formed and dispersed by infiltrating molten $\mathrm{Al}$ into a $\mathrm{Ti}$ powder or an Al-Ti mixed powder. ${ }^{14,15}$ ) The reaction temperatures of these processes reach high levels, as both process make the most of the reaction heat to promote the formation of reinforcements and the infiltration of the molten Al. The latter process also requires a complex apparatus as a controlled atmosphere is essential.

The process we applied in this study has advantages, as the intermetallic compounds formed in situ have a granular shape and can be dispersed at lower temperatures-and thus more economically - than the compounds dispersed via the previously described vortex process. In this study, we investigated how various processing variables affected the morphology of the intermetallic compounds.

\section{Experimental Procedure}

The experimental apparatus is schematically shown in Fig. 1. Molten Al (50 g, purity: $99.99 \%$ or JIS AC8A (Al12.1 mass $\% \mathrm{Si}-1.0$ mass $\% \mathrm{Cu}-1.0 \mathrm{mas} \% \mathrm{Mg}-1.2 \mathrm{mass} \% \mathrm{Ni}$ ) in a AISI304 stainless steel container $(30 \mathrm{~mm}$ inner diameter) was set in an electric furnace and kept at the desired temperatures. Various powders (mass\% from 10 to 25 ) were added onto the surface of the molten $\mathrm{Al}$ by a powder feeder 


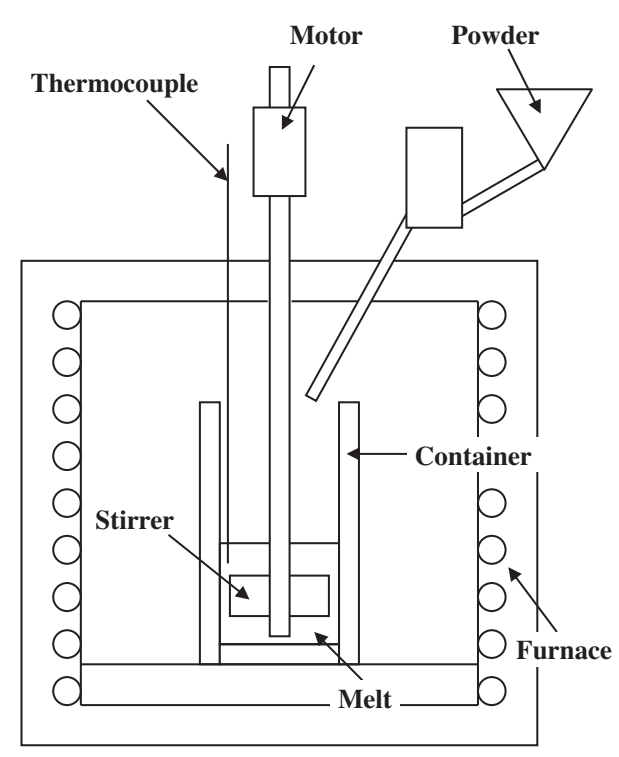

Fig. 1 Schematic illustration of experimental apparatus.

Table 1 Size and purity of powders.

\begin{tabular}{ccc}
\hline Type & $\begin{array}{c}\text { Size } \\
(\mu \mathrm{m})\end{array}$ & $\begin{array}{c}\text { Purity } \\
(\text { mass } \%)\end{array}$ \\
\hline & $3 \sim 5$ & 99.9 \\
$\mathrm{Ni}$ & $<53$ & 99 \\
& $<150$ & 99 \\
$\mathrm{Ti}$ & $<150$ & 99 \\
$\mathrm{Zr}$ & $63 \sim 90$ & 99.9 \\
$\mathrm{Cr}$ & $<150$ & 98 \\
$\mathrm{Mo}$ & $\sim 93$ & 99.9 \\
$\mathrm{~W}$ & $<150$ & 99.8 \\
$\mathrm{Fe}$ & $<150$ & 99.9 \\
\hline
\end{tabular}

using ultrasonic vibration and then stirred into the melt. Table 1 lists the sizes and purities of the powders used. All of the powders were added in air, while the $\mathrm{Zr}$ powder was also added in an Ar atmosphere. The rate of introduction was a few grams per minute. The stirrer was an $\mathrm{Al}_{2} \mathrm{O}_{3}$ plate fixed at the end of an AISI304 bar (8 mm diameter) and set at the center of the molten Al. The stirrer revolved at $2000 \mathrm{rpm}$ in the main experiments, and at 1000 or $3000 \mathrm{rpm}$ in separate experiments for comparison. After the powders were added and then constantly stirred for 5 to $30 \mathrm{~min}$, the AISI304 container was taken out of the furnace, gradually cooled in air for $1 \mathrm{~min}$, and quenched in water. The temperature of the molten Al was measured by a K-type thermocouple immersed in the molten Al. This thermocouple was also used to control the temperature of the electric furnace, and the set temperature was that of the molten $\mathrm{Al}$ when the addition of the powder commenced. The microstructures were examined by optical microscopy of the longitudinal cross sections of the columnar samples. Energy dispersive X-ray spectroscopy (EDX) and an X-ray diffraction analysis (XRD) were used to determine the phase compositions.

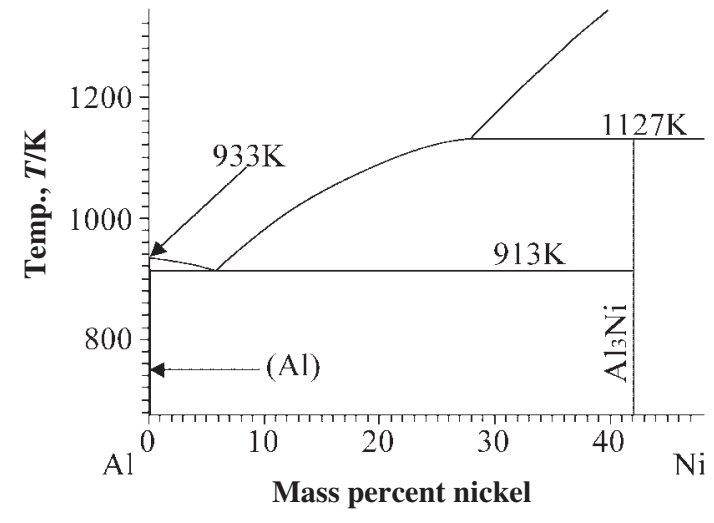

Fig. 2 Phase diagram for Al-rich side of Al-Ni binary system.

\section{Results and Discussion}

\subsection{Al-Ni system}

\subsubsection{Microstructure}

The phase diagram of the Al-rich side of the Al-Ni system $^{16)}$ is shown in Fig. 2. When the Al-20 mass\% Ni alloy was gradually cooled from $1123 \mathrm{~K}$ in a furnace and quenched in water at $1003 \mathrm{~K}$, a coarse and needle-like $\mathrm{Al}_{3} \mathrm{Ni}$ intermetallic compound precipitated as the primary phase, as shown in Fig. 3(a). Figure 3(b) shows the solidification microstructure obtained under the same condition used to obtain the microstructure shown in Fig. 3(a), but with stirring of the molten $\mathrm{Al}$ at $1000 \mathrm{rpm}$. The microstructure in Fig. 3(b) is clearly similar to the needle-like $\mathrm{Al}_{3} \mathrm{Ni}$ microstructure observed in Fig. 3(a), but with fragmentation due to stirring and a somewhat coarser grade. The shear force of the stirring probably prevented the $\mathrm{Al}_{3} \mathrm{Ni}$ from growing into the needlelike form exhibited in Fig. 3(a). For reference, the cooling rates of the samples shown in Figs. 3(a) and (b) before water-quenching were 4.84 and $4.89 \mathrm{~K} / \mathrm{min}$, respectively. Figure 3(c) shows the solidification microstructure of the molten pure $\mathrm{Al}$ mixed with 20 mass $\%$ Ni powder (under $53 \mu \mathrm{m}$ ) and stirred at $2000 \mathrm{rpm}$ for $30 \mathrm{~min}$. The fine $\mathrm{Al}_{3} \mathrm{Ni}$ compounds were homogeneously dispersed. This morphology is typical of this process and is expected to improve the mechanical properties.

There has been some apprehension that the AISI304 container and molten $\mathrm{Al}$ may react in this type of process. Though we have yet to discount this possibility, we found no Fe compounds in the solidification microstructures of the samples fabricated at the lower temperature and low stirring rate used in the present experiments.

\subsubsection{Change in temperature}

Figure 4 shows the temperature change in the molten $\mathrm{Al}$ induced by the addition of $\mathrm{Ni}$ powder. The Ni powder (under $53 \mu \mathrm{m}$ ) was added to the molten pure $\mathrm{Al}$ at $973 \mathrm{~K}$, hence the heat of reaction (1) (standard enthalpy of formation at $973 \mathrm{~K}$ ) increased the temperature of the melt up to the first peak.

$$
3 \mathrm{Al}+\mathrm{Ni}=\mathrm{Al}_{3} \mathrm{Ni}-190 \mathrm{~kJ} / \mathrm{mol}^{17)}
$$

After the first peak, the temperature dipped, rose to a second peak near the end of the addition, and gradually dropped back to the set temperature of $973 \mathrm{~K}$. We attributed these temperature changes to the following series of events. As the stable 


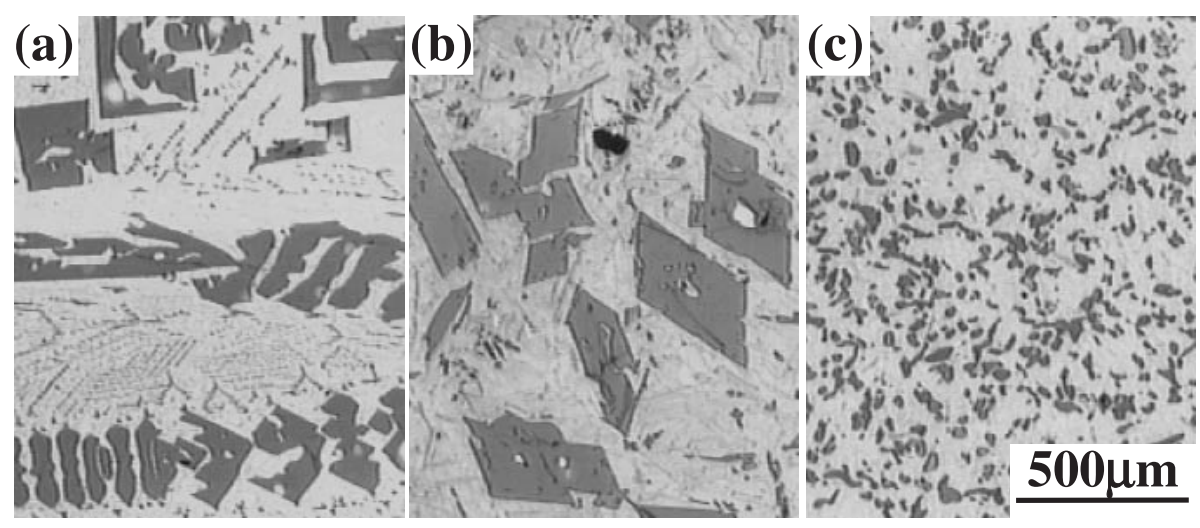

Fig. 3 Optical micrographs of Al-20 mass\%Ni alloy for various processes: (a) no stirring, (b) stirring, (c) Ni powder addition and stirring.

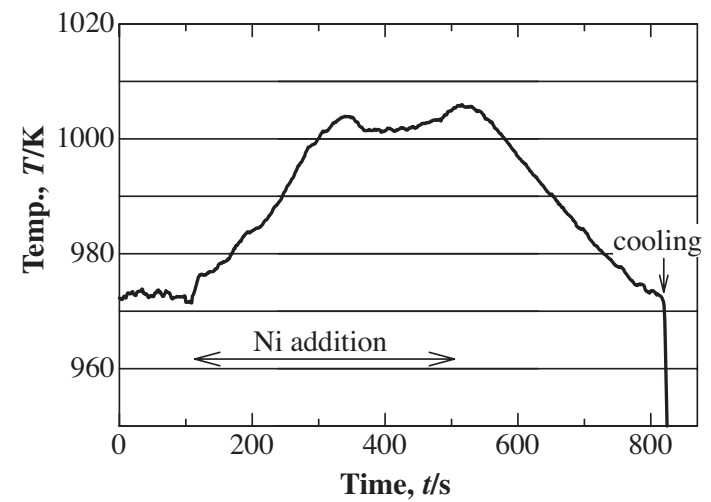

Fig. 4 Temperature change of molten $\mathrm{Al}$ with Ni addition.

phase is a single phase of liquid when the powder is first added, the molten $\mathrm{Al}$ and the Ni powder rapidly react. Within seconds, all of the added Ni powder is therefore changed to $\mathrm{Al}_{3} \mathrm{Ni}$ and it dissolves in the melt. Next, when the $\mathrm{Ni}$ concentration saturates, the reaction between the molten $\mathrm{Al}$ and the Ni powder gradually slows down until it involves only the surface of the $\mathrm{Ni}$ powder. As the amount of $\mathrm{Ni}$ contributing to the reaction thus decreases, the temperature of the melt decreases along with it. The subsequent increase in the temperature, the second peak, results from the increase in the amount of reacting $\mathrm{Ni}$ powder due to its successive addition.

In the case of Fig. 4, the rate of addition was $1.9 \mathrm{~g} / \mathrm{min}$. As the rate of addition increased, the temperature increase of the melt tended to accelerate in parallel. This rate must be carefully controlled, as the intermetallic compounds will grow dendritic (see Fig. 3) if the temperature finally rises above liquidus.

\subsubsection{Reaction between powder and melt}

Figure 5 shows the solidification microstructure of molten pure $\mathrm{Al}$ mixed with 20 mass $\% \mathrm{Ni}$ powder (under $53 \mu \mathrm{m}$ ) at $943 \mathrm{~K}$ and quenched in water seconds after the powder addition. A spot EDX analysis confirmed an $\mathrm{Al}_{3} \mathrm{Ni}$ phase (darkened areas in Fig. 5), an un-reacted Ni phase at the center of the powder, and an intermediate $\mathrm{Al}_{3} \mathrm{Ni}_{2}$ phase between the $\mathrm{Al}_{3} \mathrm{Ni}$ and un-reacted $\mathrm{Ni}$. No other intermetallic compounds were detected. These observations were consistent with a report by Hibino on the rate of formation of $\mathrm{Ni}-\mathrm{Al}$

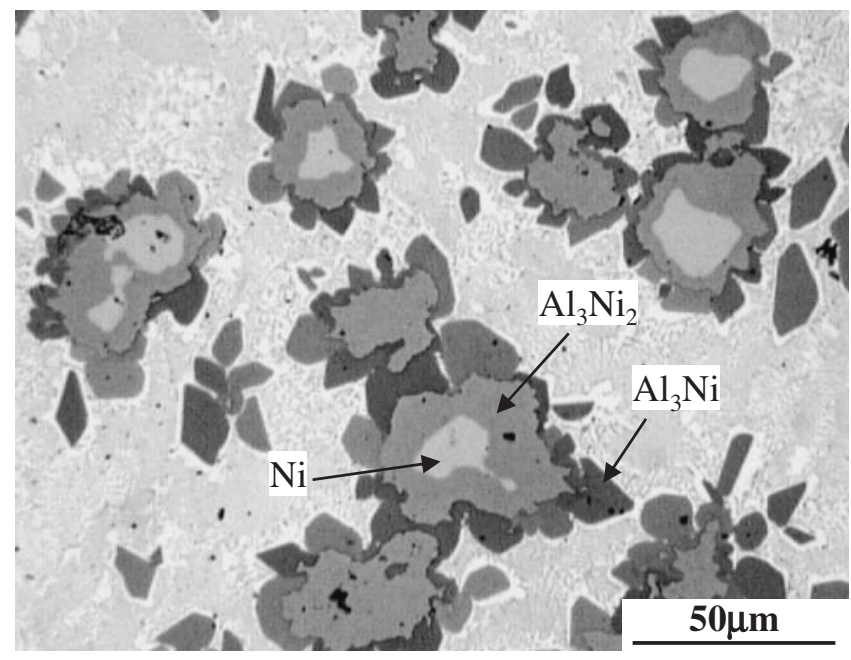

Fig. 5 Reaction between molten $\mathrm{Al}$ and $\mathrm{Ni}$ powder.

intermetallic compounds. ${ }^{18)}$ As seen in Fig. 5, the Ni powder does not instantly react and change to $\mathrm{Al}_{3} \mathrm{Ni}$ as soon as it is added. On the contrary, the reaction with the molten $\mathrm{Al}$ gradually proceeds, working inward towards the center of the $\mathrm{Ni}$ powder from the outer surface, and the $\mathrm{Al}_{3} \mathrm{Ni}$ particles smaller than the added $\mathrm{Ni}$ powder are dispersed into the matrix as a result of the stirring.

In light of the densities of the $\mathrm{Ni}, \mathrm{Al}_{3} \mathrm{Ni}_{2}$, and $\mathrm{Al}_{3} \mathrm{Ni}$, i.e., $8.9 \times 10^{3}, 4.8 \times 10^{3}$, and $4.0 \times 10^{3} \mathrm{~kg} / \mathrm{m}^{3},{ }^{19)}$ respectively, the Ni powder is thought to undergo an expansion reaction with the molten Al. The stress induced by the expansion probably works together with the shear force to refine the $\mathrm{Al}_{3} \mathrm{Ni}$.

\subsection{Effects of processing variables on the microstruc- ture}

\subsubsection{The effect of the revolution rate}

Figure 6 shows the solidification microstructures of the molten pure $\mathrm{Al}$ mixed with 20 mass $\% \mathrm{Ni}$ powder (under $53 \mu \mathrm{m}$ ) and stirred at various revolution rates for $10 \mathrm{~min}$ after the powder addition. The microstructures formed under the faster stirring conditions tended to consist of the finer $\mathrm{Al}_{3} \mathrm{Ni}$. We presume, in this case, that the increased shear force induced by the higher revolution separated the $\mathrm{Al}_{3} \mathrm{Ni}$ from the Ni powder before it could grow large on the surface of the 


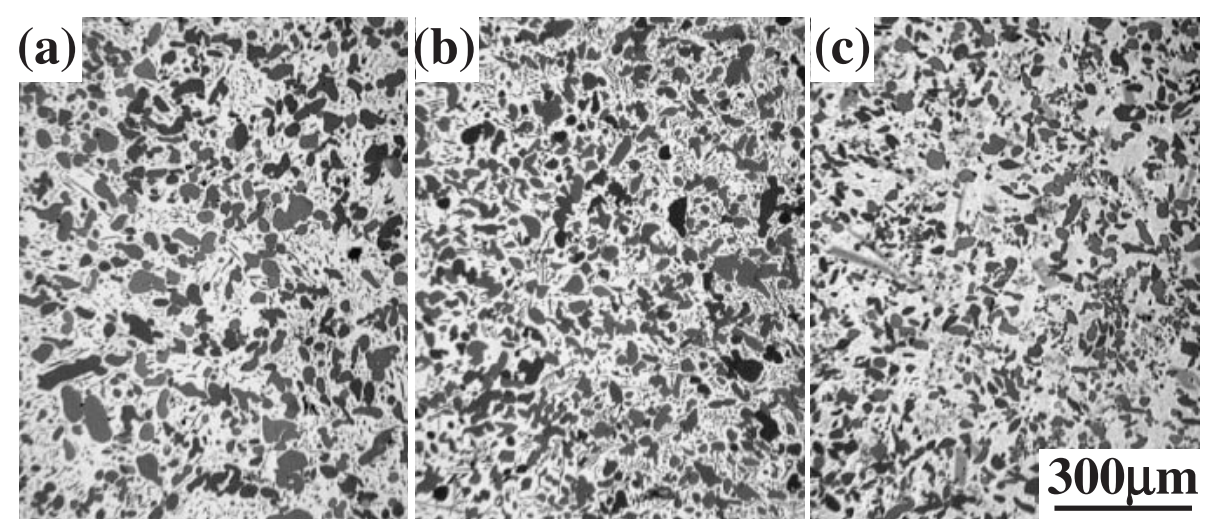

Fig. 6 Influence of revolution rate on microstructure: (a) $1000 \mathrm{rpm}$, (b) $2000 \mathrm{rpm}$, (c) $3000 \mathrm{rpm}$.

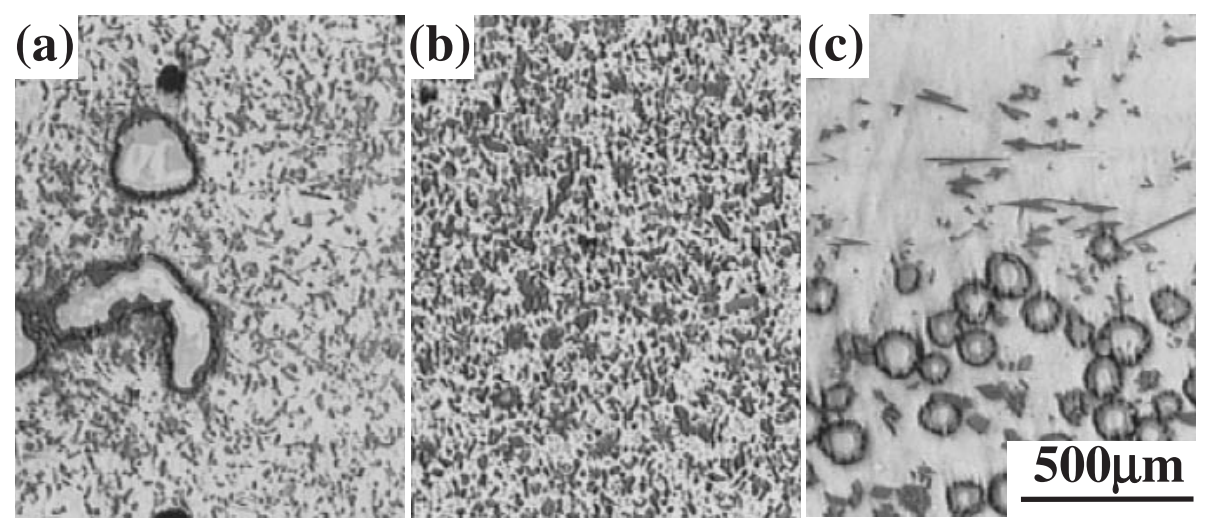

Fig. 7 Influence of the size of the Ni power on microstructure: (a) $3 \sim 5 \mu \mathrm{m}$, (b) $<53 \mu \mathrm{m}$, (c) $<150 \mu \mathrm{m}$.

Ni powder. In another test conducted at a revolution rate of $500 \mathrm{rpm}$, the stirring was too slow to generate a vortex or to pull any of the $\mathrm{Ni}$ powder down into the melt from the surface. The microstructure formed under the rapid stirring condition of $3000 \mathrm{rpm}$ also included needle-like $\mathrm{Fe}$ compounds (Fig. 6(c)), presumably from the reaction between the AISI304 container and molten Al.

\subsubsection{The effect of the size of the Ni powder}

Figure 7 shows the solidification microstructures of the molten pure $\mathrm{Al}$ mixed with 20 mass $\% \mathrm{Ni}$ powders of various sizes at $943 \mathrm{~K}$ and continuously stirred for $5 \mathrm{~min}$ after the powder addition. The microstructure formed from the relatively fine powder contained coarse compounds generated from the reaction between the segregated powder and molten $\mathrm{Al}$ (Fig. 7(a)). We attribute this to the method used to add the powder. Unable to automatically feed the powder using the powder feeder described in section 2, we had to manually introduce it little by little. When introduced in this discontinuous manner, the powder was likely to agglomerate. In the microstructures prepared using the relatively coarse powder, on the other hand, much of the Ni powder apparently settled due to the specific gravity difference at the lower part of the specimen with the un-reacted Ni phase (Fig. 7(c)). The microstructure prepared with the medium-grade powder exhibited a homogenous dispersion of fine $\mathrm{Al}_{3} \mathrm{Ni}$ and no visible traces of $\mathrm{Ni}$ powder with an un-reacted $\mathrm{Ni}$ phase (Fig. 7(b)).

According to Stoke's law, the sedimentation velocity of a

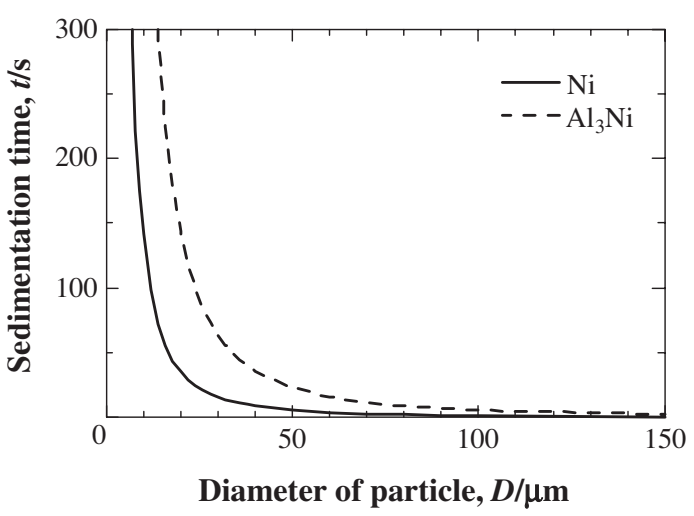

Fig. 8 Sedimentation time for $\mathrm{Ni}$ and $\mathrm{Al}_{3} \mathrm{Ni}$ particles as a function of diameter.

spherical particle through a motionless fluid is given by equation (2).

$$
v=\frac{g \cdot D^{2} \cdot\left(\rho_{p}-\rho_{f}\right)}{18 \cdot \mu}
$$

where $g$ is the acceleration due to gravity, $D$ is the particle diameter, $\rho_{P}$ is the particle density, $\rho_{f}$ is the density of the fluid, and $\mu$ is the viscosity of the fluid. This equation can be used to estimate the time it takes for a compound to sediment to a height of $50 \mathrm{~mm}$, the sedimentation height of molten Al. Figure 8 plots the sedimentation time when the $\rho_{p}$ values are 


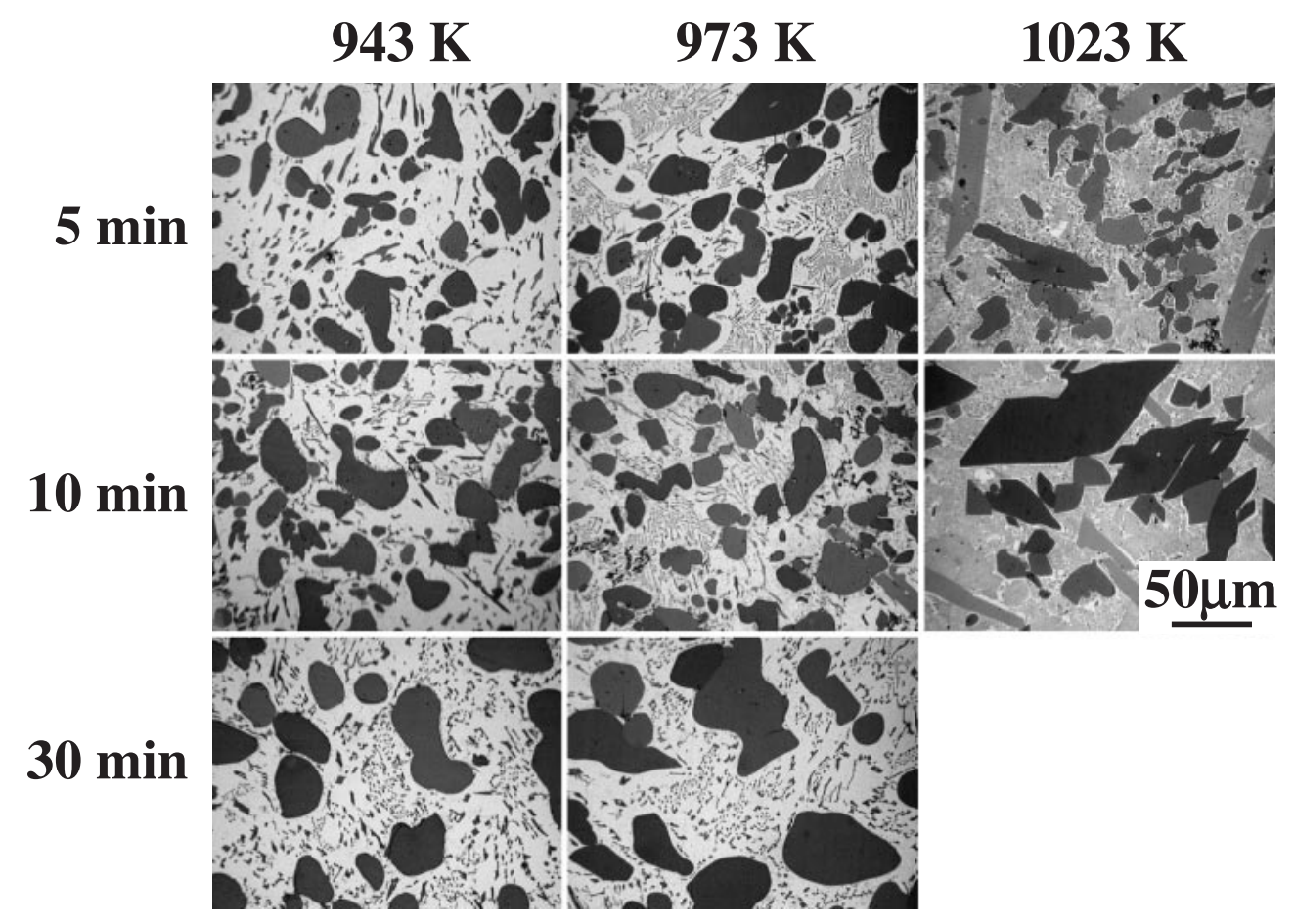

Fig. 9 Influence of the temperature of molten $\mathrm{Al}$ alloy and the stirring time on the microstructure.

defined as the densities of $\mathrm{Al}_{3} \mathrm{Ni}\left(4.0 \times 10^{3} \mathrm{~kg} / \mathrm{m}^{3}\right)$ and $\mathrm{Ni}$ $\left(8.9 \times 10^{3} \mathrm{~kg} / \mathrm{m}^{3}\right), \rho_{f}$ is defined as the density of the molten $\mathrm{Al}$ at $973 \mathrm{~K}\left(2.4 \times 10^{3} \mathrm{~kg} / \mathrm{m}^{320)}\right)$, and the viscosity of the molten $\mathrm{Al}$ is assumed to be that of water $(0.001 \mathrm{~Pa} \cdot \mathrm{s})$. As we clearly see, the sedimentation time significantly decreases when the size of the compound increases and when a powder with an un-reacted $\mathrm{Ni}$ phase is applied.

Under our experimental conditions, it took $1 \mathrm{~min}$ from the completion of the stirring before the melt was quenched. In the microstructure formed with the coarsest powder $(150 \mu \mathrm{m})$, the powder settled to the lower part of the specimen in accordance with the previous result, as shown in Fig. 7(c). We attribute this to the relatively large particle size of the added $\mathrm{Ni}$ powder and the un-reacted large $\mathrm{Ni}$ phase in the powder. Given that the viscosity of the molten $\mathrm{Al}$ increases as the solid fraction increases, the sedimentation time in Fig. 8 could conceivably shift to a longer-time profile.

When we compare the diameters of the $\mathrm{Al}_{3} \mathrm{Ni}$ particles dispersed in the matrix, the microstructure in Fig. 7(a) has the finest morphology. In other words, the finer $\mathrm{Ni}$ powder generated a finer grade of $\mathrm{Al}_{3} \mathrm{Ni}$. If we had been able to continuously introduce the fine powder, presumably we would have obtained a dispersion of exclusively fine $\mathrm{Al}_{3} \mathrm{Ni}$. In addition, the use of a fine $\mathrm{Ni}$ powder can shorten the processing time (the time required for the complete reaction of all the $\mathrm{Ni}$ with the molten $\mathrm{Al}$ ).

\subsubsection{Effects of the stirring time and molten Al temper-} ature

Figure 9 shows the solidification microstructures of molten pure Al mixed with 20 mass $\% \mathrm{Ni}$ powder (under $53 \mu \mathrm{m}$ ) at various temperatures and continuously stirred for various times after the powder addition. In the batch stirred for $5 \mathrm{~min}$, all of the $\mathrm{Ni}$ powder reacted to form $\mathrm{Al}_{3} \mathrm{Ni}$. The morphology of $\mathrm{Al}_{3} \mathrm{Ni}$ was granular at 943 and $973 \mathrm{~K}$, but mostly needle-like at $1023 \mathrm{~K}$, as shown in Fig. 3. The addition of the Ni powder at $1023 \mathrm{~K}$ increased the temperature of the molten $\mathrm{Al}$ to $1073 \mathrm{~K}$. Thus, the temperature did not rise to liquidus; i.e., $1087 \mathrm{~K}$ for the $\mathrm{Al}-20$ mass $\% \mathrm{Ni}$, the target composition. The temperature of the molten $\mathrm{Al}$ probably increased above the liquidus locally, however, and the generation of $\mathrm{Al}_{3} \mathrm{Ni}$ with a needle-like and coarse morphology probably took place during cooling. Figure 9 also shows the increase in the size of the $\mathrm{Al}_{3} \mathrm{Ni}$ in parallel with the increasing stirring time. This change is probably attributable to Ostwald ripening and the combinations formed by pairs of colliding particles.

\subsubsection{The effect of the amount of added Ni powder}

Figure 10 shows the solidification microstructures of molten pure $\mathrm{Al}$ mixed with various amounts of $\mathrm{Ni}$ powder (under $53 \mu \mathrm{m}$ ) at $943 \mathrm{~K}$ and continuously stirred for $10 \mathrm{~min}$ after the powder addition. An increase in the amount of $\mathrm{Ni}$ powder led to an increase in the amount of $\mathrm{Al}_{3} \mathrm{Ni}$, as expected from Fig. 2. The coarseness of the $\mathrm{Al}_{3} \mathrm{Ni}$ also tended to increase as more $\mathrm{Ni}$ was added. This enhanced coarsening of the $\mathrm{Al}_{3} \mathrm{Ni}$ can be attributed to two factors: first, the longer addition times and stirring times required for the additions of progressively larger amounts of Ni powder; and second, the increase in the temperature of the molten $\mathrm{Al}$ induced by the increase in the total heat of formation. Taken together, these results suggest that we can produce materials with dispersed $\mathrm{Al}_{3} \mathrm{Ni}$ of a proper size and fraction by appropriately controlling the process variables.

\subsection{Al-Ti system}

Figure 11 shows the solidification microstructures of the molten pure $\mathrm{Al}$ mixed with Ti powder (under $150 \mu \mathrm{m}$ ) at 943 or $973 \mathrm{~K}$ and continuously stirred for 5 or $30 \mathrm{~min}$ after the 

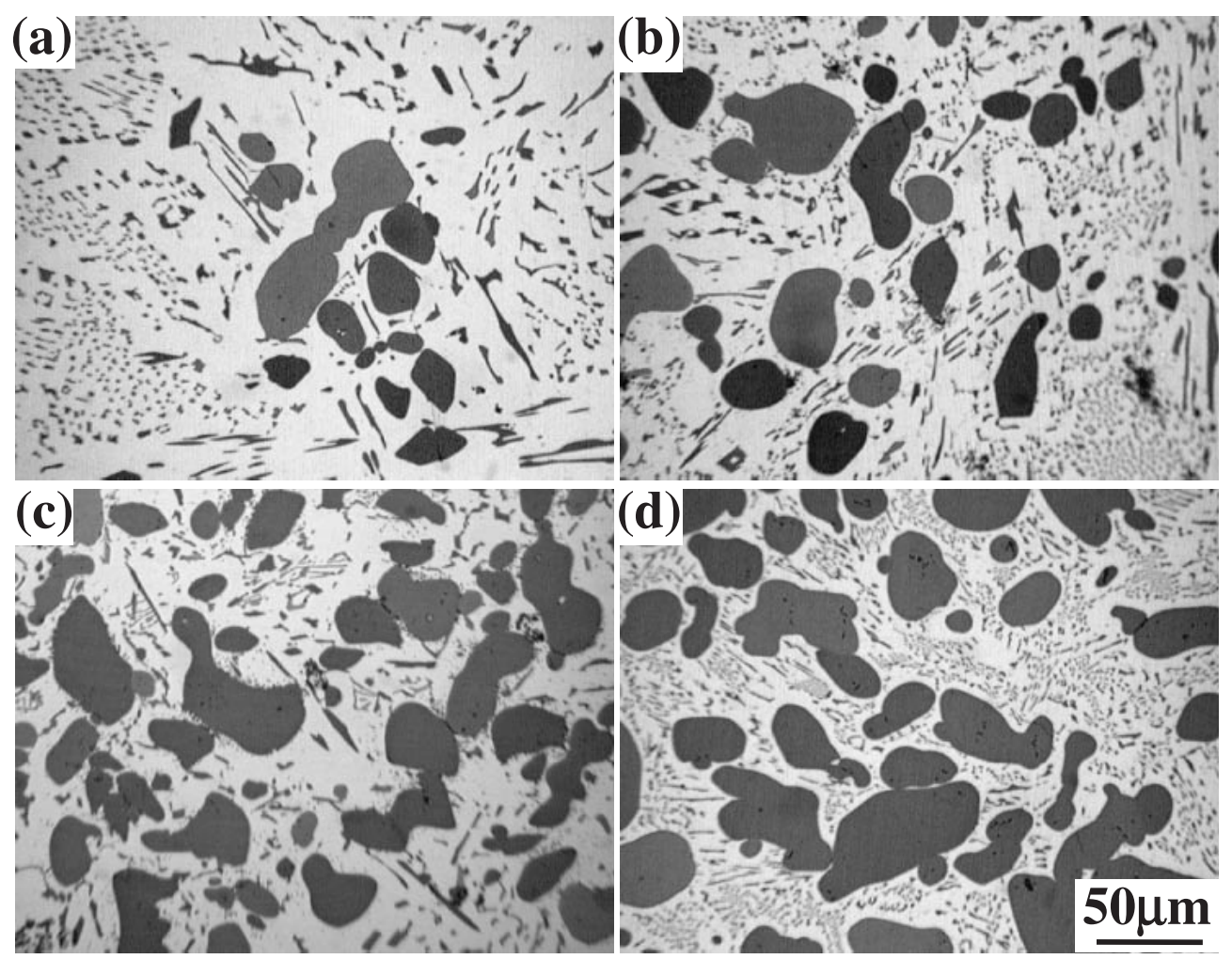

Fig. 10 Influence of the amount of $\mathrm{Ni}$ addition on the microstructure: (a) $5.6 \mathrm{~g}$, (b) $8.8 \mathrm{~g}$, (c) $12.5 \mathrm{~g}$, (d) $16.7 \mathrm{~g}$.

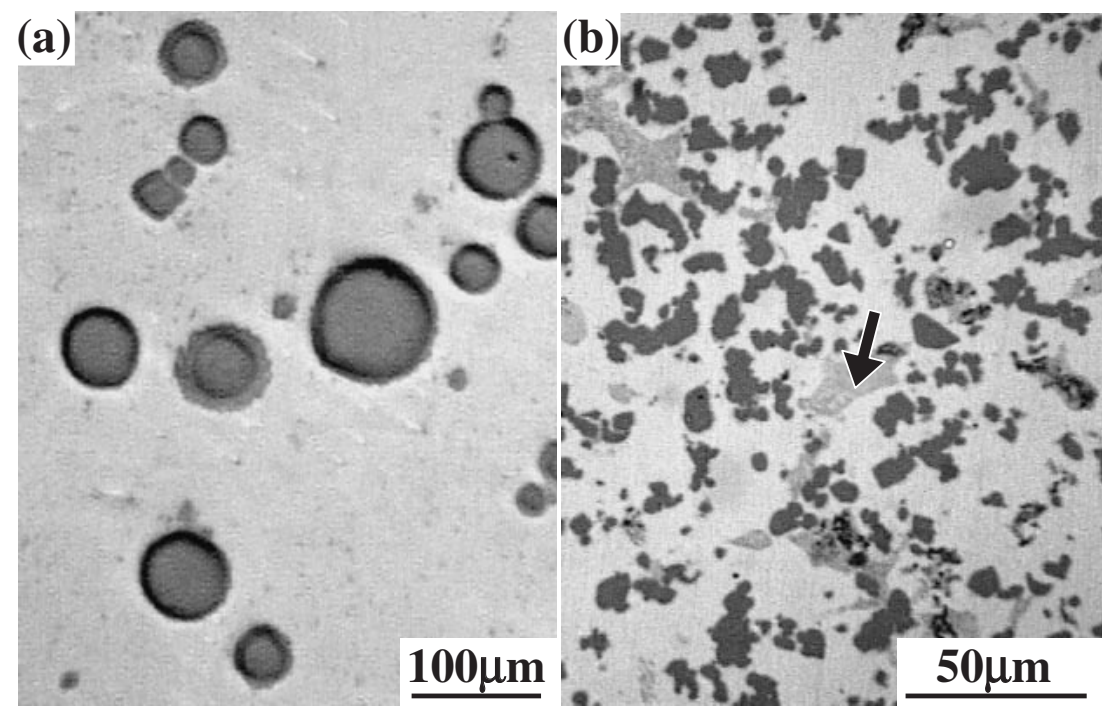

Fig. 11 Optical micrographs of Al-10 mass\% Ti alloy under various conditions: (a) Temp.: 943 K, Stirring time: 5 min. (b) Temp.: 973 K, Stirring time: $30 \mathrm{~min}$.

powder addition. In the microstructure formed under the $943 \mathrm{~K}$ mixture and the $5 \mathrm{~min}$ stirring condition (Fig. 11(a)), most of the powder exhibited an un-reacted $\mathrm{Ti}$ phase, although the surface of the Ti powder and molten $\mathrm{Al}$ reacted. In an effort to enhance the reaction between the Ti powder and molten $\mathrm{Al}$, we repeated the experiment with an increased temperature of $973 \mathrm{~K}$ and stirring time of $30 \mathrm{~min}$ (Fig. 11(b)). No traces of any un-reacted $\mathrm{Ti}$ phase were found in the microstructure, and $\mathrm{Al}_{3} \mathrm{Ti}$ was finely and homogeneously dispersed. However the latter condition apparently led to a partial dissolution of the AISI304 container and an Feenriched zone was found in the microstructure (see the arrow in Fig. 11(b)). These results indicate that the process in this study can be applied to the Al-Ti system as well as the Al-Ni system. The main difference between the two systems is reactivity; the $\mathrm{Ti}$ powder is less reactive to $\mathrm{Al}$ than the $\mathrm{Ni}$ powder. The heat of formation (standard enthalpy of formation at $973 \mathrm{~K}), 181 \mathrm{~kJ} / \mathrm{mol},{ }^{20)}$ is comparable to that of $\mathrm{Al}_{3} \mathrm{Ni}, 190 \mathrm{~kJ} / \mathrm{mol}$. In our experiments, however, the temperature increase induced by the addition of the $\mathrm{Ni}$ powder 

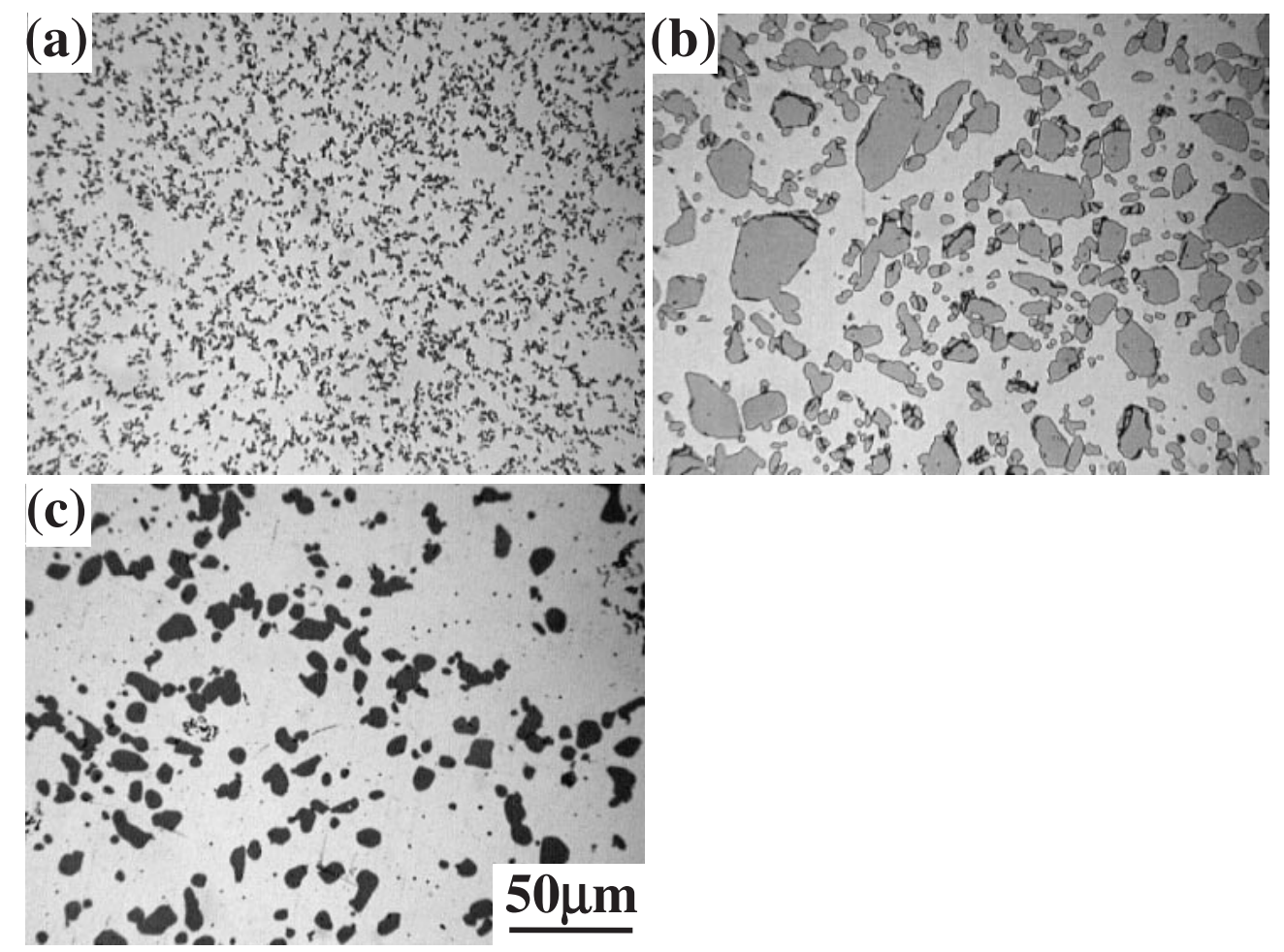

Fig. 12 Optical micrographs of intermetallic compounds dispersed aluminum alloys: (a) $\mathrm{Al}_{3} \mathrm{Zr}$, (b) $\mathrm{Al}_{7} \mathrm{Cr}$, (c) $\mathrm{Al}_{12} \mathrm{Mo}$.

(under $150 \mu \mathrm{m}$ ) was $38 \mathrm{~K}$. On the other hand, the addition of a $\mathrm{Ti}$ powder of the same grade as the Ni powder above did not induce any apparent increase in the temperature of the molten Al. In separate experiments using a relatively fine Ti powder (63 to $90 \mu \mathrm{m}$ ), however, we observed no apparent increase in the temperature of the molten $\mathrm{Al}$, and most of the powder exhibited an un-reacted Ti phase. These findings might have been due to the effects of the powder oxidation. Such details will be discussed in the next section.

\subsection{Other systems}

Figure 12 shows the solidification microstructures of molten pure $\mathrm{Al}$ mixed with 10 mass $\% \mathrm{Zr}, \mathrm{Cr}$, or Mo powder at $943 \mathrm{~K}$ and continuously stirred for 5 to $10 \mathrm{~min}$ after the powder addition. Granular intermetallic compounds were well dispersed in the Al matrix in all cases. Moreover, the intermetallic compounds were confirmed to be in equilibrium with the $\alpha$-Al phase in the phase diagrams by X-ray diffraction. Fig. 13 shows the X-ray diffraction pattern of the specimen with $\mathrm{Zr}$ powder as an example. The $\mathrm{Zr}$ powder was added under Ar. In an earlier attempt to add the $\mathrm{Zr}$ powder in air, the powder addition induced a rapid oxidation reaction which prevented the production and homogenous dispersion of $\mathrm{Al}_{3} \mathrm{Zr}$ after only $10 \mathrm{~min}$ of stirring. On the other hand, attempts to add $\mathrm{W}$ or $\mathrm{Fe}$ powder to the molten $\mathrm{Al}$ resulted in a segregation of the powder at the surface and bottom of the melt, a condition which prevented dispersion of the intermetallic compounds.

The result of the $\mathrm{Zr}$ powder addition suggests that the oxidation of the metal powder influenced the difference in the dispersion behavior of the intermetallic compounds. Metal powders must be wetted with molten $\mathrm{Al}$ if intermetallic compounds are to be formed. However, when a powder is

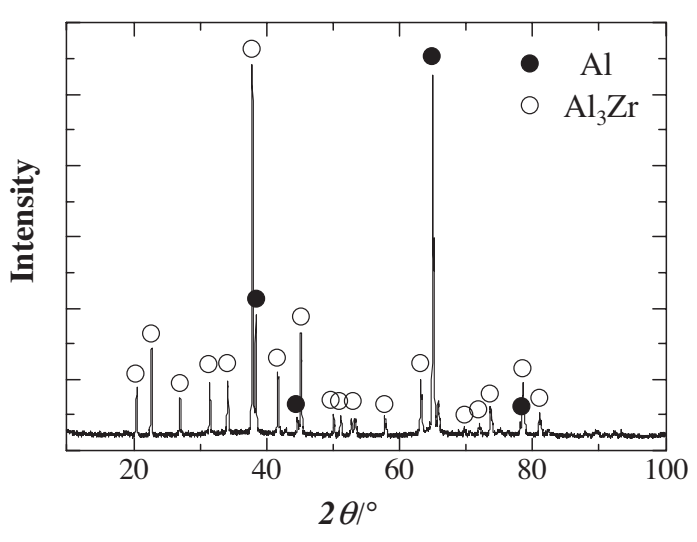

Fig. 13 X-ray diffraction pattern of Al-Zr alloy.

oxidized by air before it enters molten $\mathrm{Al}$, its wettability in the molten $\mathrm{Al}$ declines and the oxidized powder segregates without reacting at the surface and bottom of the melt. As reported in a previous section, the Ti powder is less reactive to $\mathrm{Al}$ than the Ni powder. The lower reactivity of the former is probably attributable to the barrier effect of the Ti powder oxide layer. Even if the powder is oxidized, it can be deoxidized by the thermite reaction with the molten Al. Table 2 shows the standard free energy of formation of representative oxides at $943 \mathrm{~K} .{ }^{17)}$ Given that all of the oxides except $\mathrm{ZrO}_{2}$ have lower values than $\mathrm{Al}_{2} \mathrm{O}_{3}$, we know that thermite reactions are possible. However, sufficient contact between the powder and molten $\mathrm{Al}$ is a necessary condition. In the experiment with the $\mathrm{W}$ powder, the powder settled to the bottom of the melt due to the high density of $\mathrm{W}$ relative to that of the molten Al. Thus, the absence of the thermite 
Table 2 Gibbs standard free energy of oxide formation at $943 \mathrm{~K}$.

\begin{tabular}{lllr} 
& & & $\left(\mathrm{kJ} / \mathrm{mol} \mathrm{O}_{2}\right)$ \\
\hline $\mathrm{NiO}$ & -308 & $\mathrm{MoO}_{2}$ & -415 \\
$\mathrm{TiO}_{2}$ & -772 & $\mathrm{WO}_{2}$ & -411 \\
$\mathrm{ZrO}_{2}$ & -921 & $\mathrm{Fe}_{3} \mathrm{O}_{4}$ & -402 \\
$\mathrm{Cr}_{2} \mathrm{O}_{3}$ & -589 & $\mathrm{Al}_{2} \mathrm{O}_{3}$ & -921 \\
\hline
\end{tabular}

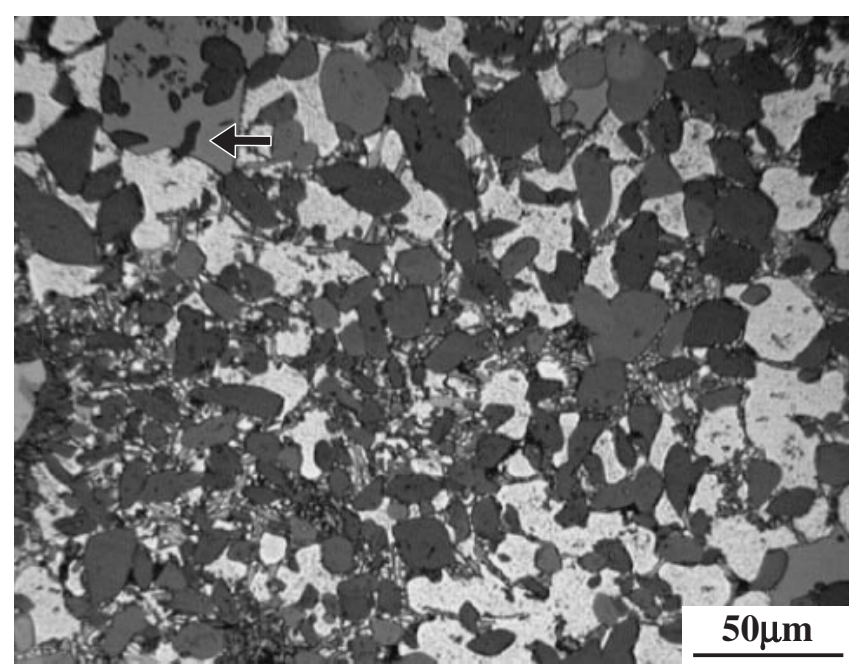

Fig. 14 Optical micrograph of $\mathrm{AC} 8 \mathrm{~A}-\mathrm{Al}_{3} \mathrm{Ni}$ composite.

reaction may have been partly due to the poor contact between the powder and molten $\mathrm{Al}$.

In summary, the dispersion behavior of intermetallic compounds is influenced by the oxidation rate, the rate of the thermite reaction, and the density difference between the powder and melt, as well as the rate of formation of intermetallic compounds induced by the direct reaction between the metal powder and melt.

There were considerable differences in the sizes of the intermetallic compounds which were homogeneously dispersed. The $\mathrm{Al}_{3} \mathrm{Zr}$ particles, the smallest, were only a few micrometers in diameter. Thus, the particles sizes of the produced intermetallic compounds were clearly very dependent on the specific elemental metal powder added. Further investigations into the finer details of the reaction processes will elucidate the reasons for this.

\subsection{Application to an alloy in service}

In the previous sections, we described the properties of the microstructures of pure $\mathrm{Al}$ with various added metal powders. In pursuit of practical applications, we applied the same process to JIS AC8A, an alloy with an excellent heat resistance and wear resistance among the various JIS Al alloys currently in use. Figure 14 shows the solidification microstructure of the molten AC8A alloy mixed with $\mathrm{Ni}$ powder (under $53 \mu \mathrm{m}$ ) at $853 \mathrm{~K}$. The amount of the $\mathrm{Ni}$ powder was 20 mass $\%$ and the stirring was continued for 10 min after the powder addition. Though coarse Si was observed in some portions of the microstructure (indicated by the arrow in Fig. 14), the dark gray areas indicationg granularly-shaped $\mathrm{Al}_{3} \mathrm{Ni}$ were homogeneously dispersed. On the basis of this result, we believe that the process is probably applicable to various $\mathrm{Al}$ alloys. By optimizing the composition of the Al matrix, we expect to produce new Albased composites with a high hardness and other attractive properties typically seen in intermetallic compounds.

\section{Conclusion}

We have tried to produce new materials reinforced with homogenous dispersions of fine intermetallic compounds by adding metal powder to molten $\mathrm{Al}$ and stirring the melt to induce the formation of intermetallic compounds in situ. The important results are listed below.

(1) The intermetallic compounds produced by the process applied in our experiments tend to be fine and granular, though they exhibit a coarse and needle-like morphology in conventional castings.

(2) The sizes of the intermetallic compounds formed in situ decrease as the size of added metal powder decreases.

(3) Lower process temperatures and reduced stirring times refine the intermetallic compounds.

(4) The sizes of the intermetallic compounds formed in situ are highly dependent on the types of added metal powders.

(5) The process investigated in this study can be applied to various transition metals and molten $\mathrm{Al}$ alloys.

\section{REFERENCES}

1) K. Hatsuyama, J. Hiraiwa, K. Yamauchi, J. Kato and O. Osawa: SOKEIZAI 42 (2001) 20-25.

2) T. Suganuma: J. JFS. 73 (2001) 829-833.

3) F. A. Badia and P. K. Rohatgi: Trans. AFS. 77 (1969) 402-406.

4) M. Banerji, M. K. Surappa and P. K. Rohatgi: Metal. Trans. 14B (1983) 273-283.

5) T. Choh, Z. Ebihara and T. Oki: J. Jpn. Inst. Light Met. 38 (1988) 600607.

6) R. Mehrabian, R. G. Riek and M. C. Flemings: Metall. Trans. 5 (1974) 1899-1905.

7) V. M. Bermudez: Appl. Phys. Lett. 42 (1983) 70-71.

8) H. Nakae, H. Fujii, B. Zhao and T. Shinohara: J. JFS. 75 (2003) 545551.

9) H. Nakata, T. Choh and N. Kanetake: J. Jpn. Inst. Light Met. 43 (1993) $152-158$.

10) H. Nakata and T. Choh: J. Japan Inst. Metals 57 (1993) 1317-1324.

11) M. Tsujikawa, T. Hashimoto and M. Kawamoto: IMONO 64 (1992) 526-530.

12) M. Kobashi and T. Choh: J. Jpn. Inst. Light Met. 42 (1992) 138-142.

13) N. Omura, M. Kobashi, T. Choh and N. Kanetake: J. Jpn. Inst. Met. 66 (2002) 1317-1324.

14) T. Y. Um and R. Watanabe: J. Japan Inst. Metals 58 (1994) 559-563.

15) K. Mizuuchi, T. Takeuchi, M. Fukusumi, M. Sugioka and H. Nagai: J. Jpn. Inst. Met. 62 (1998) 551-556.

16) T. B. Massalski et.al. (Ed.): Binally Alloy Phase Diagrams, (American Society for Metals, 1986).

17) O. Kubaschewski, C. B. Alcock and P. J. Spencer (Ed.): Material Thermochemistry, Sixth Edition, (Pergamon Press, 1993).

18) A. Hibino: J. Japan Inst. Metals 57 (1993) 767-773.

19) JCPDS: International Centre for Diffraction Data.

20) The Japan Institute of Metals, Kinzoku data book (3rd ed.): (1993). 